\title{
Bacterial Endo-Symbiont Inhabiting Tridax procumbens L. and Their Antimicrobial Potential
}

\author{
Syed Baker, ${ }^{1}$ Kumara Shanthamma Kavitha, ${ }^{1}$ Huvinakola Chinnappa Yashavantha Rao, ${ }^{1}$ \\ Devaraju Rakshith, ${ }^{1}$ Ballagere Puttaraju Harini, ${ }^{2}$ \\ Komal Kumar, ${ }^{3}$ and Sreedharamurthy Satish ${ }^{1,4}$
}

${ }^{1}$ Herbal Drugs Technological Laboratory, Department of Studies in Microbiology, Manasagangotri, University of Mysore, Mysore, Karnataka 570 006, India

${ }^{2}$ Department of Zoology, Bangalore University, Jnanabharathi Campus, Bangalore, Karnataka 560 056, India

${ }^{3}$ Department of Clinical and Experimental Medicine, Linköping University, 58185 Linköping, Sweden

${ }^{4}$ Department of Plant Pathology, University of Georgia, Athens, GA 30602, USA

Correspondence should be addressed to Sreedharamurthy Satish; satish.micro@gmail.com

Received 22 August 2015; Revised 23 October 2015; Accepted 28 October 2015

Academic Editor: Rajesh Jeewon

Copyright (C) 2015 Syed Baker et al. This is an open access article distributed under the Creative Commons Attribution License, which permits unrestricted use, distribution, and reproduction in any medium, provided the original work is properly cited.

Bacterial symbionts inhabiting Tridax procumbens L. were screened for antimicrobial potential with the aim to isolate potent bacteria bearing significant activity against test pathogens. The selected isolate was subjected to large scale fermentation to extract antimicrobial metabolite. The organic phase was reduced under vacuum pressure and crude ethyl acetate extract $(10 \mathrm{mg} / \mathrm{mL}) \mathrm{was}$ evaluated for antimicrobial activity against panel of test pathogens. The antibacterial activity was measured as a zone of inhibition and compared with standard antibiotics, gentamicin and tetracycline. Similarly, antifungal activity was compared with miconazole and bavistin. Significant activity was conferred against Shigella flexneri (MTCC 731) with $27 \pm 1.5 \mathrm{~mm}$ zone across the disc. Partially, purification of antimicrobial metabolite with TLC-bioautography and HPLC resulted in active fraction bearing activity at $R_{f} 0.65$ and eluting between 4 and 5 retention times. The obtained results are promising enough for future purification and characterization of antimicrobial metabolite. Thus, the study attributes to the growing knowledge on endophytes as one of the rich sources of antimicrobial potentials.

\section{Introduction}

In recent years, microbial entities inhabiting medicinal plants are considered to be one of the rich novel sources of bioactive compounds bearing activities. In view of the ongoing efforts to combat drug resistant microbial pathogens, scientific communities are focusing on these microbial symbionts. It is well documented that every plant species is reported to inhabit diverse consortium of microbial symbionts which are known as endophytes [1]. These endophytes reside inside healthy tissues of plants and secrete bioactive metabolites bearing biological activities like antimicrobial, antitumor, antidiabetic, anti-inflammatory, antioxidant, and so forth [2]. Perusal of literatures confers the majority of studies conducted on fungal endophytes compared to bacterial endophytes which are known to be one of the dominant microbial communities colonizing the inner tissues [3]. Owing to these facts, the present study aims to screen bacterial endophytic symbionts from medicinal Tridax procumbens $\mathrm{L}$. The selection of plant was carried out based on the traditional knowledge and prior investigation on endophytes. Earlier study demonstrates antibacterial activity of crude extract from endophytes Colletotrichum sp. and Alternaria sp. isolated from Tridax procumbens L. [4]. Tridax procumbens L. is reported to possess significant medicinal value and is used as medicine in developing countries by tribal community for its wound healing properties. Studies also envision Tridax procumbens $\mathrm{L}$. for antioxidant, antimicrobial, hepatoprotective, antiinflammatory, and anticancerous properties [5]. Hence, the present investigation attributes to the growing scientific knowledge on endophytes as one of the merited microbial sources towards secreting antimicrobial metabolites. 


\section{Materials and Methods}

2.1. Sample Collection. The plant material (Tridax procumbens L.) samples were collected from "Chamundi Hills" reserve forest $\left(12^{\circ} 15^{\prime} 34^{\prime \prime}-12^{\circ} 17^{\prime} 5^{\prime \prime}\right.$ north to $76^{\circ} 39^{\prime} 63^{\prime \prime}$ $76^{\circ} 42^{\prime} 02^{\prime \prime}$ east) that comprises an isolated range of hillocks ranging in altitude from 861 to $944 \mathrm{~m}$ above sea level, surrounding a plateau that is $1,024-1,057 \mathrm{~m}$ high with a periphery of $11 \mathrm{~km}$, situated southeast at Mysore city, Karnataka, Southern part of India. Fresh and healthy samples were collected in a sterile polythene bags and brought to the laboratory and processed within $24 \mathrm{~h}$. The selected plant was identified, authenticated, and deposited at the Department of Studies in Botany, University of Mysore, with accession number 721 . The collected plants were thoroughly washed with tap water to remove soil and dirt particles and then immersed in double distilled water containing $50 \mu \mathrm{g} / \mathrm{mL}$ of cycloheximide for $60 \mathrm{~min}$ to suppress the growth of fungal endophytes [3].

2.2. Surface Sterilization for Strains Isolation. Stem, leaves, and root segments of T. procumbens were subjected to surface sterilization under aseptic condition by sequential steps of immersion in $3.15 \%$ sodium hypochlorite for $5 \mathrm{~min}$, followed by ethanol $70 \%$ for $30 \mathrm{sec}$. Later, the outer tissue of surface sterilized stem, roots, and leaves were excised with sterilized scalpel into $0.5-1.0 \mathrm{~cm}$ tissue blocks and placed onto nutrient agar supplemented with $250 \mu \mathrm{g} / \mathrm{mL}$ of cycloheximide and incubated till bacterial endophytic colonies were visible. To confirm that the surface disinfestations process was successful and to verify that there is no biological contamination from the surface during the surface sterilization protocol, sterility checks were carried out for each step to monitor the effectiveness by plating $0.1 \mathrm{~mL}$ of final rinse onto nutrient plates which served as control $[3,6]$.

\subsection{Primary Screening of Endophytic Bacterial Isolates for Antimicrobial Activity}

2.3.1. Test Strains. Eleven different strains of human and phytopathogenic microorganism, namely, Bacillus subtilis (MTCC 121), Escherichia coli (MTCC 7410), Salmonella typhi (MTCC 733), Shigella flexneri (MTCC 731), Staphylococcus aureus (MTCC 7443), Staphylococcus epidermidis (MTCC 435), Xanthomonas campestris (MTCC 7908), and Candida albicans (MTCC 183), were obtained from IMTECH-MTCC Chandigarh, India. Fusarium verticillioides, Aspergillus niger, and Aspergillus flavus were procured from DANIDA Laboratory, Mysore.

2.4. Primary Screening of Antimicrobial Potential. Antibacterial activity was evaluated by agar overlay method. Endophytic isolates were point-inoculated and incubated for 3 days at $37^{\circ} \mathrm{C}$. Later, colonies were inactivated by inverting the upper lid with $1-5 \mathrm{~mL}$ chloroform for $40 \mathrm{mins}$. The inactivated colonies were overlaid with $5 \mathrm{~mL}$ of sloppy soft agar with $0.65 \%$ nutrient agar that had been inoculated with the test organisms. Zones of inhibition around the colonies were recorded after $24 \mathrm{~h}$ of incubation at $37^{\circ} \mathrm{C}$. Endophytic bacteria exhibiting activity were further subjected to scale production to extract the bioactive metabolites [7]. Similarly, antifungal activity was performed by dual culture method [8]. Endophytic isolate was streaked perpendicularly onto the potato dextrose agar medium, wherein agar plugs taken from an actively growing fungal culture were placed across the streak of bacterial isolate. Simultaneously, a control plate was maintained without any streaking of isolate and plates were incubated at room temperature for 3-4 days and observed for suppression of fungal growth.

2.5. Large Scale Fermentation of Potent Isolate. Based on the results from preliminary screening, endophyte bearing antimicrobial potential was subjected to large scale fermentation. Actively growing colony was aseptically inoculated into 1-litre Erlenmeyer flasks and incubated at $32^{\circ} \mathrm{C}$ with $120 \mathrm{rpm}$ (rotation per minute) on rotary incubatory shaker. The samples were periodically monitored for increase in optical density at $600 \mathrm{~nm}$ with Shimadzu double beam spectrophotometer (Shimadzu Corp., Kyoto, Japan) [9].

2.6. Extraction and Analytical Detection of Metabolite. The supernatant obtained from fermentation of active isolate was extracted with ethyl acetate in the ratio $1: 1(\mathrm{v}: \mathrm{v})$ and the organic phase was reduced under vacuum pressure at $40^{\circ} \mathrm{C}$ until dryness. The obtained dry mass was weighed and dissolved in minimal amount of ethyl acetate to obtain crude extract at concentration $10 \mathrm{mg} / \mathrm{mL}$ for further studies.

\subsection{Evaluation of Antimicrobial Activity}

2.7.1. Disc Diffusion Assay. Antibacterial activity was determined using the disc diffusion method. In brief, prewarmed MHA (Mueller-Hinton agar) plates were seeded with $10^{6} \mathrm{CFU}$ (colony forming unit) suspensions of test bacteria and $50 \mu \mathrm{L}$ crude ethyl acetate extract at $10 \mathrm{mg} / \mathrm{mL}$ (milligram/millilitre) was impregnated onto sterile paper discs $(6 \mathrm{~mm}$ diameter $)$ and placed on the surface of inoculated agar plates in triplicate. Plates were incubated at $37^{\circ} \mathrm{C}$ for $24 \mathrm{~h}$. Antibacterial activity was measured as the diameter of the zone of inhibition across the disc. The results were interpreted and validated using ethyl acetate as negative control, and gentamicin at $1 \mathrm{mg} / \mathrm{mL}$ concentration (for antibacterial) and Bavistin at $1 \mathrm{mg} / \mathrm{mL}$ concentration (for antifungal) were used as positive control [10].

2.7.2. Bioautography. The active fraction bearing antimicrobial potential was determined with bioautography assay. Crude extract was partially purified using TLC plates with mobile phase ethyl acetate and methanol at a ratio $1: 1$. The developed TLC plates were overlaid with 1-2 mm layer of soft medium BHI (Brain Heart Infusion agar 0.6\%), supplemented with $0.1 \%(\mathrm{w} / \mathrm{v})$ 2,3,5-triphenyltetrazolium chloride (tetrazolium red) and previous seeded test organisms at a final concentration of $10^{7} \mathrm{CFU} / \mathrm{mL}$. The plates were placed in a sterile tray, sealed to prevent the thin agar layer from drying, and incubated at $37^{\circ} \mathrm{C}$ for $24 \mathrm{hrs}$ (hours); the plates were run in duplicate [11]. 


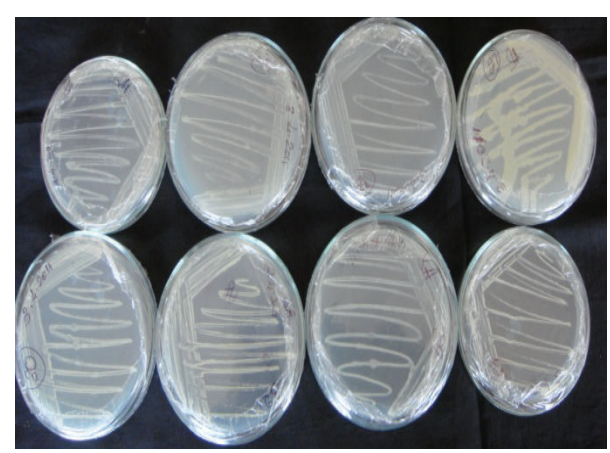

Isolates

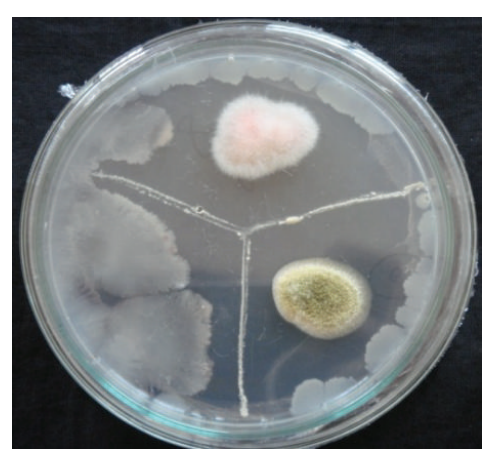

Perpendicular streak

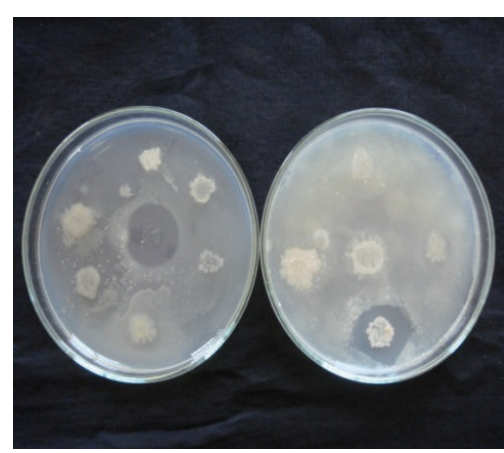

Agar overlay

FIGURE 1: Pure culture of isolates and primary screening via streak plate assay along with agar overlay.
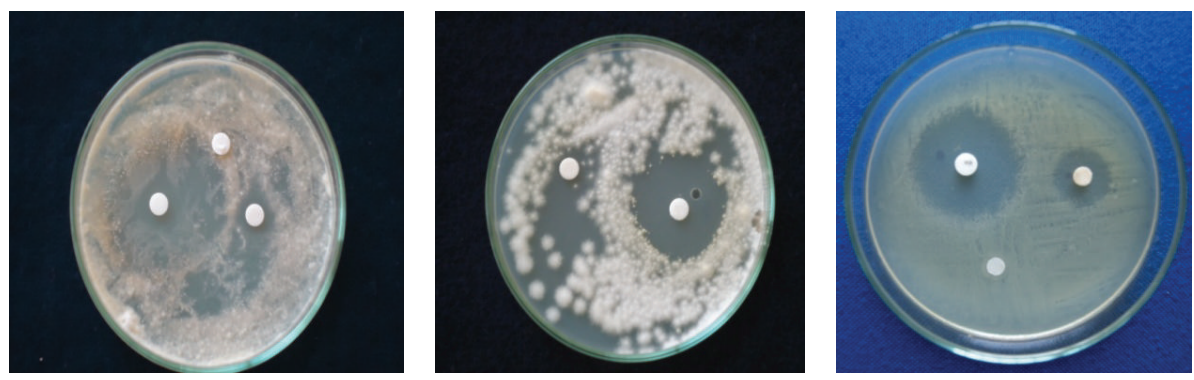

Antimicrobial activity

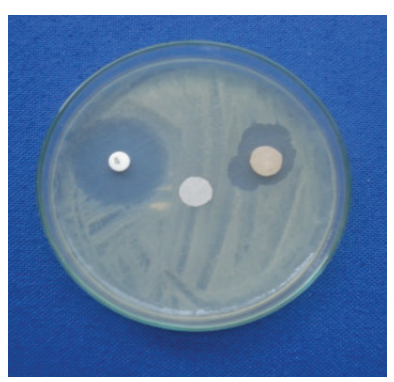

Figure 2: Antimicrobial activity of crude extract obtained from T28.

2.8. Partial Purification with HPLC. The crude ethyl acetate extract was partially purified using HPLC coupled with C18 column. The mobile phase was with HPLC-grade water (component $\mathrm{A}$ ) and acetonitrile (component $\mathrm{B}$ ) in gradient mobile phase in linear mode consisting initially of $\mathrm{A} / \mathrm{B}$ and increasing up to $100 \% \mathrm{~B}$ in 30 minutes at flow rate of $1 \mathrm{~mL} \mathrm{~min}^{-1}$ and injection volume at $10 \mu \mathrm{L}$ with UV detector system at $220 \mathrm{~nm}$. The eluting fractions were collected and visualized for band on TLC.

\section{Results}

Screening of Tridax procumbens L. for bacterial symbionts was successful with successive sterilization process. Use of cycloheximide during surface sterilization of leaves, stem, and roots segments suppressed the growth of endophytic fungi which resulted in the isolation of bacterial endophytes. The bacterial isolates were designated with alphanumeric codes T 01 to T 29 and preserved until further experiments. Isolates were dominant from surface sterilized stem with fourteen isolates identified from plant, six isolates from leaves, and nine isolates from roots, respectively. All the isolates exhibited myriad morphological characteristic and were subjected to preliminary screening which resulted in the inhibition of test fungal pathogens, namely, F. verticillioides, A. niger, and A. flavus, with perpendicular streak of isolates across the test pathogen (Figure 1). Agar overlay method for bacteria displayed clear zone of inhibition on the layer of test pathogenic bacteria laid over point-inoculated endophytic bacteria (Figure 1). Based on the results ascertained from primary screening, one potent endophytic bacterium which displayed activity against all the test pathogens was selected as the subject of interest for large scale fermentation.

3.1. Evaluating Antimicrobial Activity. The crude ethyl acetate extract displayed antimicrobial activity by disc diffusion method against test pathogens with clear zone of inhibition across the disc (Figure 2). The obtained results showed the highest activity against Shigella flexneri (MTCC 731) followed by Staphylococcus aureus (MTCC 7443), and the least activity was conferred against Xanthomonas campestris (MTCC 7908) which was tabulated and interpreted with standards gentamicin and nystatin (Table 1).

3.2. TLC-Bioautography. Thin layer chromatography of ethyl acetate obtained from endophytic isolate T28 displayed separated bands at different $R_{f}$ values with solvent system 1:1 hexane and ethyl acetate. The partially purified bioactive metabolite bearing antimicrobial activity showed prominent band at $R_{f} 0.65$ with clear zone of inhibition against test pathogen onto a red coloured background against MRSA strain as shown in Figure 3.

3.3. Partial Purification of Crude Extract. Partial purification of crude ethyl acetate extract was carried out with analytical technique HPLC; each fraction eluting was evaluated for antimicrobial potential upon which dominant peak bearing antimicrobial activity was eluted between 4 and 5 retention 
TABLE 1: Antimicrobial activity of crude ethyl acetate extract against test pathogens.

\begin{tabular}{|c|c|c|c|}
\hline \multirow{2}{*}{ Sl no. } & \multirow{2}{*}{ Test pathogens } & Ethyl acetate extract & Standard \\
\hline & & \multicolumn{2}{|c|}{ Zone of inhibition $(\mathrm{mm})$} \\
\hline \multirow[t]{7}{*}{$\mathrm{I}$} & Human pathogenic bacteria & & \\
\hline & Bacillus subtilis (MTCC 121) & $13 \pm 1.5$ & $23 \pm 1.5(\mathrm{G})$ \\
\hline & Escherichia coli (MTCC 7410) & $12 \pm 1.5$ & $26 \pm 1.5(\mathrm{G})$ \\
\hline & Salmonella typhi (MTCC 733) & $18 \pm 1.5$ & $23 \pm 1.5(\mathrm{G})$ \\
\hline & Shigella flexneri (MTCC 731) & $27 \pm 1.5$ & $32 \pm 1.5(\mathrm{G})$ \\
\hline & Staphylococcus aureus (MTCC 7443) & $23 \pm 1.5$ & $31 \pm 1.5(\mathrm{G})$ \\
\hline & Staphylococcus epidermidis (MTCC 435) & $14 \pm 1.5$ & $20 \pm 1.5(\mathrm{G})$ \\
\hline \multirow[t]{2}{*}{ II } & Plant pathogenic bacteria & & \\
\hline & Xanthomonas campestris (MTCC 7908) & $10 \pm 1.5$ & $24 \pm 1.5(\mathrm{~T})$ \\
\hline \multirow[t]{2}{*}{ III } & Human pathogenic fungi & & \\
\hline & Candida albicans (MTCC 183) & $16 \pm 1.5$ & $23 \pm 1.5(\mathrm{M})$ \\
\hline \multirow[t]{4}{*}{ IV } & Plant pathogenic fungi & & \\
\hline & Fusarium verticillioides & $14 \pm 1.5$ & $24 \pm 1.5(\mathrm{~B})$ \\
\hline & Aspergillus niger & $10 \pm 1.5$ & $19 \pm 1.5(\mathrm{~B})$ \\
\hline & Aspergillus flavus & $13 \pm 1.5$ & $22 \pm 1.5(\mathrm{~B})$ \\
\hline
\end{tabular}

Values are zone of inhibition in mean \pm standard error.

Note. $\mathrm{G}=$ gentamicin, $\mathrm{T}=$ tetracycline, $\mathrm{M}=$ miconazole, and $\mathrm{B}=$ Bavistin.

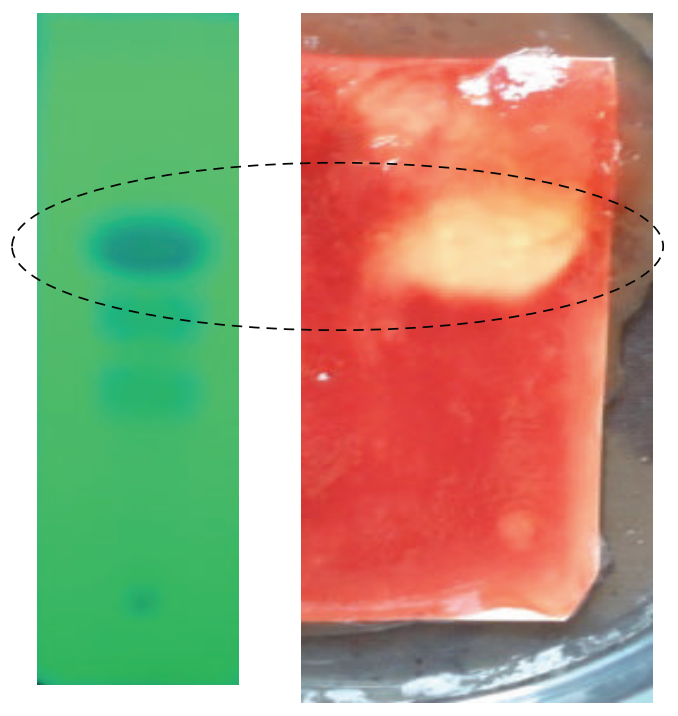

TLC-bioautography

FIGURE 3: TLC-bioautography of crude extract obtained from T28 against MRSA.

times (Figure 4) which was collected and verified resulting in activity against all the test pathogens.

\section{Discussion}

The results obtained in the present investigation are promising enough towards the ongoing efforts to combat multidrug resistant microorganisms. The use of plant origin products has served mankind since ancient era, but slow growing rate and harvesting of rare endangered species pose a risk and imbalance to the biodiversity of plants. Hence,

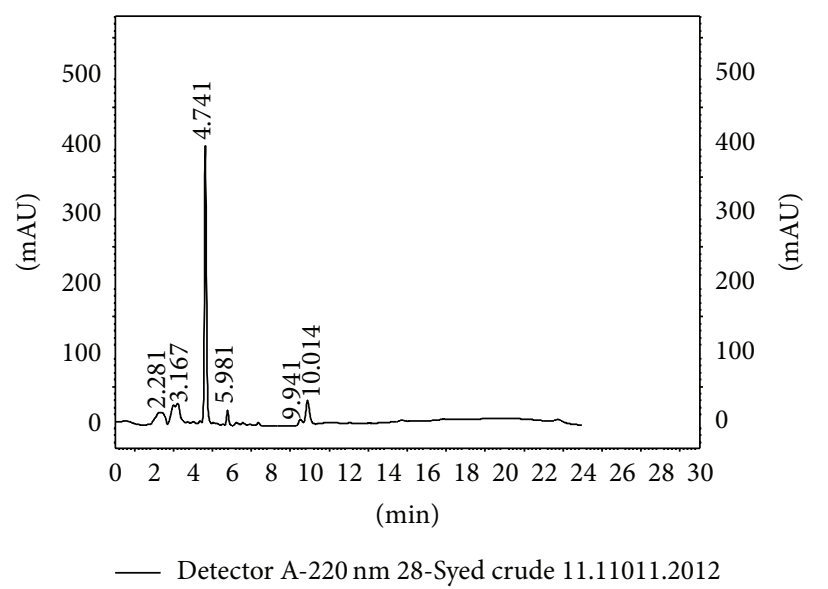

FiguRE 4: HPLC chromatogram of crude ethyl acetate extract.

scientific communities are reaching beyond plant kingdom for inexhaustible source of antimicrobial metabolites with economical feasibility and minimize the high cost [12]. Microbial flora form one of the largest diverse biological entities on the planet. Associations of these microbial entities with higher organisms have incremented their new roles and secondary metabolites with significant biological activities. One such plethora of microbial community is endophytic microorganisms which live as symbionts in almost every plant species. Research on endophytes has envisioned new interesting facets; hence, the present study was to screen and evaluate bacterial symbionts inhabiting Tridax procumbens L. for antimicrobial potentials. Screening of endophytes from plant reported to have medicinal value is one of the immense important criteria to discover potent endophytes as earlier reports confer that endophytes mimic the host 
chemistry and secrete the bioactive compound similar to that of its host. Hence, in the present investigation, Tridax procumbens $\mathrm{L}$. was selected for isolation of endophytes; earlier studies on endophytes from this plant are pertaining to fungal endophytes wherein the present study reports the evaluation of endophytic bacteria for antimicrobial potential [2]. In order to achieve potent endophytes, successful surface sterilization is critical factor. There are various surface sterilization protocols and different disinfectants such as sodium hypochlorite, mercuric chloride, ethanol, and calcium carbonate $[13,14]$. But the majority of reports suggest the use of sodium hypochlorite coupled with ethanol for the isolation of endophytes [15-17], based on which sodium hypochlorite and ethanol were used in the present investigation, which resulted in the isolation of 29 bacterial endophytes. In order to screen for antimicrobial potential, each isolate was subjected for preliminary screening with agar overlay and streak plate techniques. These techniques are reported as accurate and rapid techniques which aid in screening large number of isolates [18-20]. Based on the results ascertained from preliminary screening, only one bacterium was selected, as it displayed activity against all the test pathogens compared to other isolates. The selected isolate T28 was subjected to large scale fermentation and organic phase was extracted with ethyl acetate as a solvent to obtain crude extract. Ethyl acetate forms one of the nondestructive, nontoxic, and nonpolar solvents with low boiling point compared to others and majority of the metabolites miscible with ethyl acetate [21]. Antimicrobial activity of crude extract was carried out using disc diffusion assay. Perusal of literatures suggests that antimicrobial metabolites usually produce in lesser quantity and often bound with other secondary metabolites in crude extract which may cause synergistic effect. Hence, in order to achieve the maximum activity, $50 \mu \mathrm{L}$ crude ethyl acetate extract $(500 \mu \mathrm{g} / \mathrm{disc})$ from $10 \mathrm{mg} / \mathrm{mL}$ concentration was evaluated [22]. Significant activity was conferred against test bacteria compared to test fungus with the highest activity being displayed against Shigella flexneri which is a causative agent of Shigellosis followed by Methicillin resistant Staphylococcus aureus. Similar studies have been reported on the isolation of bacterial endophytes exhibiting antimicrobial potential [19, 23]. The active fraction of the crude extract was further partially purified with TLC and HPLC with bioautography assay, suggesting active band at $R_{f} 0.65$ bearing activity against test pathogens. The obtained results of HPLC and bioautography are congruent with earlier report of Paenibacillus polymyxa M-1, rhizobacterium exhibiting significant activity against Erwinia species.

\section{Conclusion}

The present study adds tremendous knowledge on the growing research towards developing new antimicrobial agents to combat drug resistant microorganisms. The study also contributes towards isolation of potent endophytes from Tridax procumbens $\mathrm{L}$. which has scanty reports on their microbial symbionts. Significant activity against Shigella flexneri and Methicillin resistant Staphylococcus aureus suggests that the fraction is more potent as bactericidal agent compared to antifungal. Future studies are highly recommended to characterize any novel metabolite responsible for activity.

\section{Conflict of Interests}

The authors declare that they have no conflict of interests.

\section{Acknowledgments}

The authors are thankful to RAMAN Fellowship UGC-India and CIMO-Finland for exchange program. The authors are also grateful for Department of Science and Technology (DST-SERB) for financial support and also would like to thank the Department of Studies in Microbiology, University of Mysore, for providing facilities.

\section{References}

[1] S. Baker and S. Satish, "Endophytes: toward a vision in synthesis of nanoparticle for future therapeutic agents," International Journal of Bio-Inorganic Hybrid Nanomaterials, vol. 1, no. 2, pp. 67-77, 2012.

[2] G. Strobel and B. Daisy, "Bioprospecting for microbial endophytes and their natural products," Microbiology and Molecular Biology Reviews, vol. 67, no. 4, pp. 491-502, 2003.

[3] S. Baker, P. Santhosh, D. Rakshith, and S. Satish, "Screening of bacterial endophytes inhabiting Mimosa pudica L," Scientific Journal of Microbiology, vol. 1, no. 5, pp. 136-140, 2012.

[4] R. Singh, D. Singh, V. Rathod et al., "Phytochemical analysis and antibacterial studies of the crude extracts of endophytic fungi, Colletotrichumsp. and Alternariasp. from the medicinal plant Tridax procumbens(L)," International Journal of Applied Research in Natural Products, vol. 5, no. 3, pp. 27-33, 2015.

[5] D. U. Sheshrao, K. T. Devidas, and G. Gyananath, "Preliminary screening of endophytic fungi from Tridax procumbens L. and Argemone mexicana L. for their antimicrobial activity," International Journal of Current Research, vol. 4, pp. 93-96, 2012.

[6] S. Baker, S. Sahana, D. Rakshith, H. U. Kavitha, K. S. Kavitha, and S. Satish, "Biodecaffeination by endophytic Pseudomonas sp. isolated from Coffee arabica L," Journal of Pharmacy Research, vol. 5, no. 7, pp. 3654-3657, 2012.

[7] M. Hayakava, Y. Yoshida, and Y. Limura, "Selective isolation of bioactive soil actinomycetes belonging to the Streptomyces violaceusniger phenotypic cluster," Journal of Applied Microbiology, vol. 96, no. 5, pp. 973-981, 2004.

[8] H. Lind, H. Jonsson, and J. Schnürer, "Antifungal effect of dairy Propionibacteria contribution of organic acids," International Journal of Food Microbiology, vol. 98, no. 2, pp. 157-165, 2005.

[9] S. Baker and S. Satish, "Antimicrobial evaluation of fluorescent Pseudomonas sp. inhabiting medicinal plant Annona squamosa L.", Journal of Pure and Applied Microbiology, vol. 7, no. 2, pp. 1027-1033, 2013.

[10] M. Radji, A. Sumiati, R. Rachmayani, and B. Elya, "Isolation of fungal endophytes from Garcinia mangostana and their antibacterial activity," African Journal of Biotechnology, vol. 10, no. 1, pp. 103-107, 2011.

[11] C. M. Mattana, S. E. Satorres, A. Sosa, M. Fusco, and L. E. Alcaráz, "Antibacterial activity of extracts of Acacia aroma against methicillin-resistant and methicillin-sensitive Staphylococcus," Brazilian Journal of Microbiology, vol. 41, no. 3, pp. 581$587,2010$. 
[12] S. Baker and S. Satish, "Endophytes: natural warehouse of bioactive compounds," Drug Invention Today, vol. 4, no. 11, pp. 548$553,2012$.

[13] L.-W. Wang, B.-G. Xu, J.-Y. Wang et al., "Bioactive metabolites from Phoma species, an endophytic fungus from the Chinese medicinal plant Arisaema erubescens," Applied Microbiology and Biotechnology, vol. 93, no. 3, pp. 1231-1239, 2012.

[14] H. C. Yashavantha and S. Satish, "Genomic and chromatographic approach for the discovery of polyketide antimicrobial metabolites from an endophytic Phomopsis liquidambaris CBR18," Frontiers in Life Science, vol. 8, no. 2, pp. 200-207, 2015.

[15] V. M. D. Siqueira, R. Conti, J. M. D. Araújo, and C. M. SouzaMotta, "Endophytic fungi from the medicinal plant Lippia sidoides Cham. and their antimicrobial activity," Symbiosis, vol. 53, no. 2, pp. 89-95, 2011.

[16] H. C. Yashavantha Rao, P. Santosh, D. Rakshith, and S. Satish, "Molecular characterization of an endophytic Phomopsis liquidambaris CBR-15 from Cryptolepis buchanani Roem. and impact of culture media on biosynthesis of antimicrobial metabolites," 3 Biotech, vol. 5, no. 2, pp. 165-173, 2015.

[17] D. Rakshith and S. Satish, "Endophytic mycoflora of Mirabilis jalapa L. and studies on antimicrobial activity of its endophytic Fusarium sp.," Asian Journal of Experimental Biological Sciences, vol. 2, no. 1, pp. 75-79, 2011.

[18] A. Nagpure, B. Choudhary, S. Kumar, and R. K. Gupta, "Isolation and characterization of chitinolytic Streptomyces sp. MT7 and its antagonism towards wood-rotting fungi," Annals of Microbiology, vol. 64, no. 2, pp. 531-541, 2014.

[19] J. Preveena and S. J. Bhore, "Identification of bacterial endophytes associated with traditional medicinal plant Tridax procumbens Linn.," Ancient Science of Life, vol. 32, no. 3, pp. 173-177, 2013.

[20] J. Li, G.-Z. Zhao, H.-Y. Huang et al., "Isolation and characterization of culturable endophytic actinobacteria associated with Artemisia annua L.," Antonie van Leeuwenhoek, vol. 101, no. 3, pp. 515-527, 2012.

[21] S. Skariyachan, A. G. Rao, M. R. Patil, B. Saikia, V. Bharadwaj $\mathrm{Kn}$, and J. Rao Gs, "Antimicrobial potential of metabolites extracted from bacterial symbionts associated with marine sponges in coastal area of Gulf of Mannar Biosphere, India," Letters in Applied Microbiology, vol. 58, no. 3, pp. 231-241, 2014.

[22] F. F. Campos, L. H. Rosa, B. B. Cota et al., "Leishmanicidal metabolites from Cochliobolus sp., an endophytic fungus isolated from Piptadenia adiantoides (Fabaceae)," PLoS Neglected Tropical Diseases, vol. 2, no. 12, article e348, 2008.

[23] V. C. Verma, S. K. Gond, A. Kumar, A. Mishra, R. N. Kharwar, and A. C. Gange, "Endophytic actinomycetes from Azadirachta indica A. Juss.: isolation, diversity, and anti-microbial activity," Microbial Ecology, vol. 57, no. 4, pp. 749-756, 2009. 

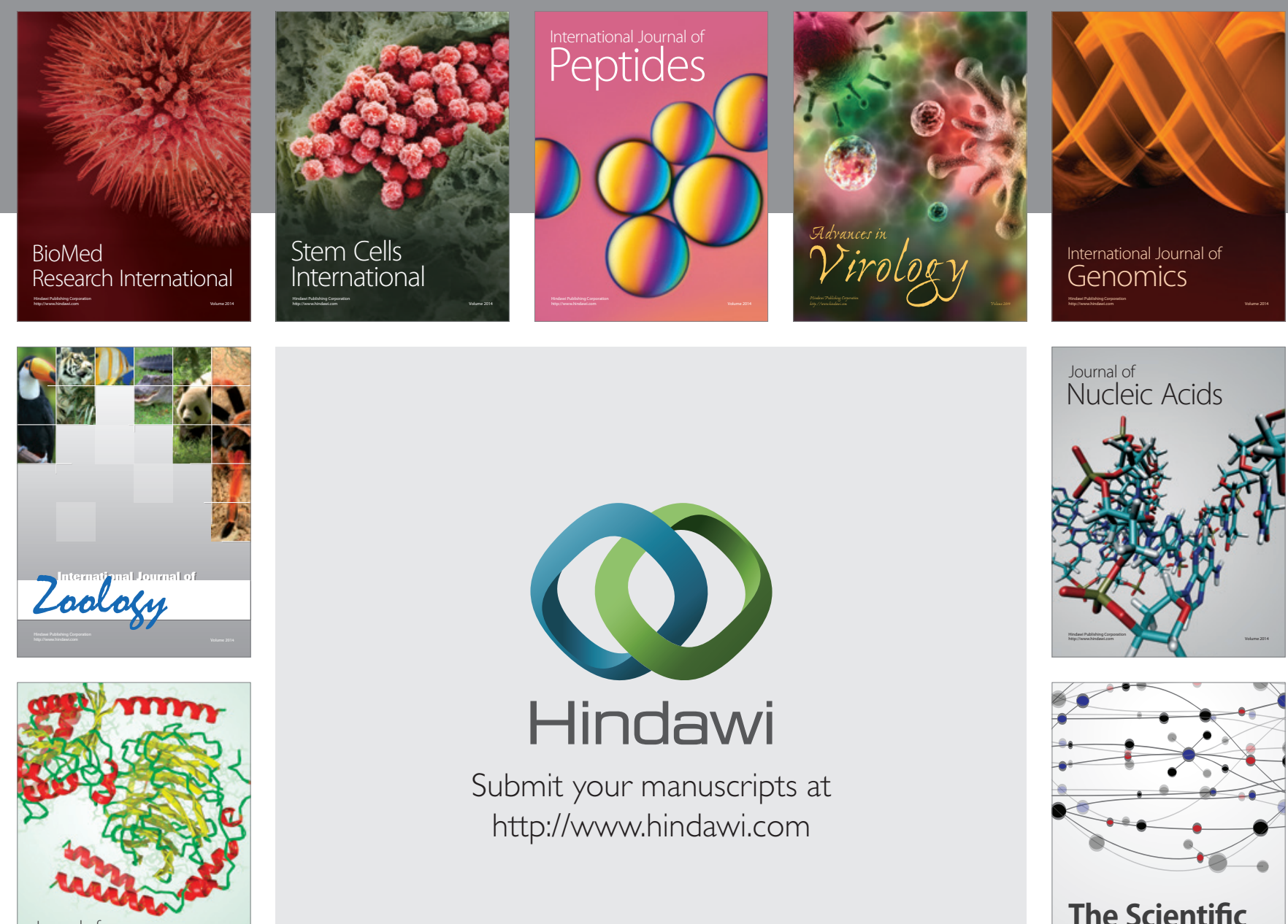

Submit your manuscripts at

http://www.hindawi.com

Journal of
Signal Transduction
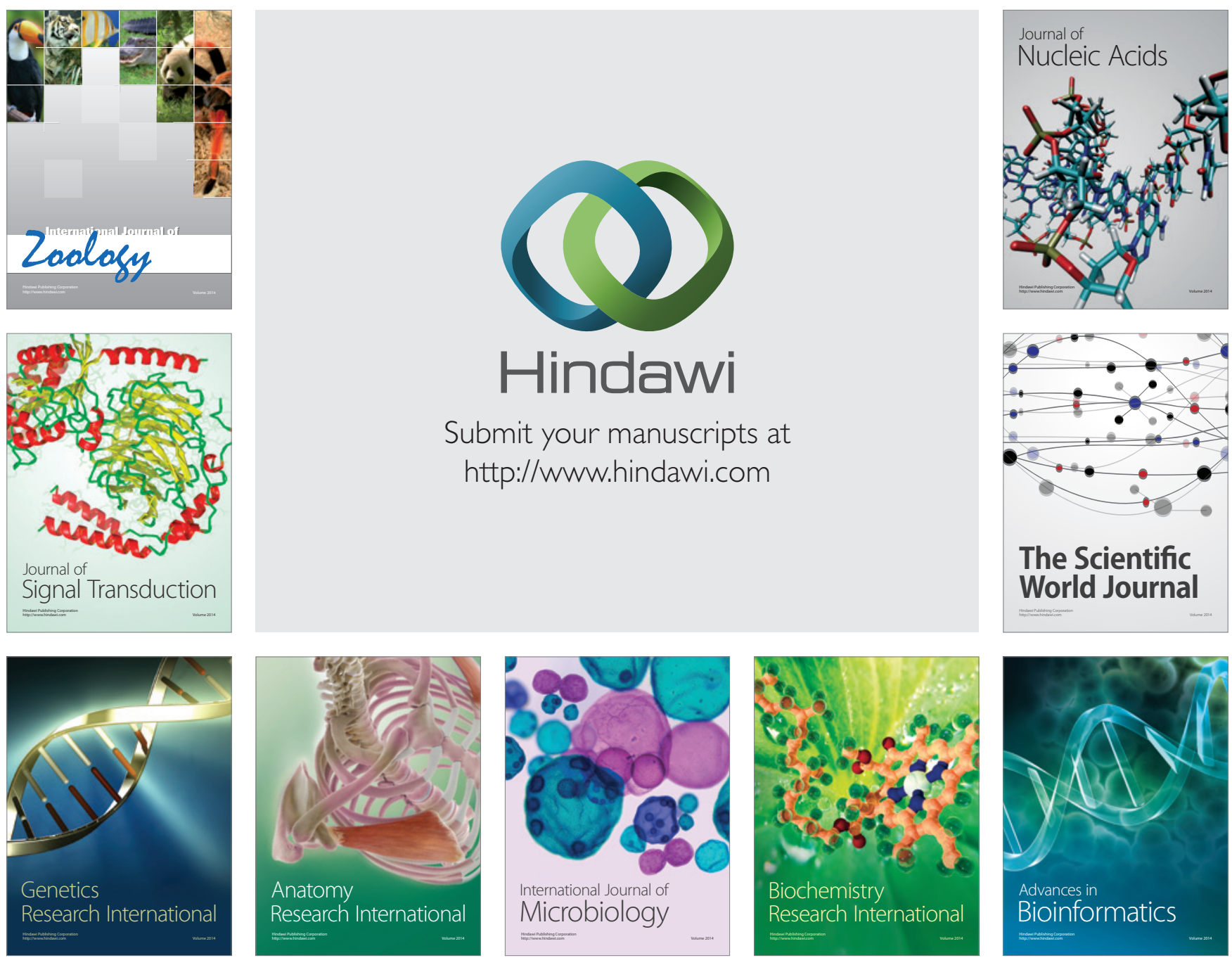

The Scientific World Journal
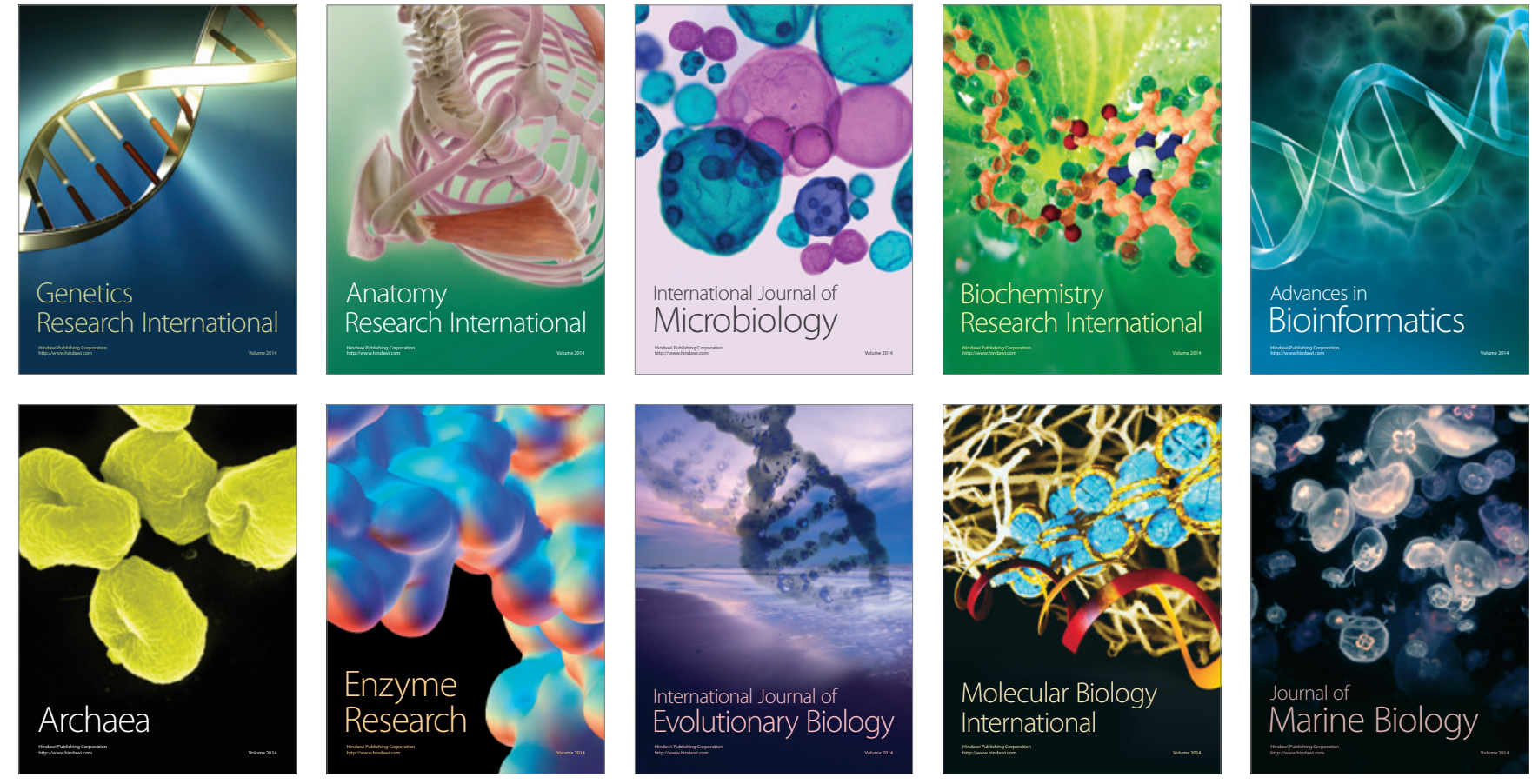